\title{
Generalized equations for predicting body density of men
}

\author{
By A. S. JACKSON* AND M. L. POLLOCK† \\ Wake Forest University, Winston-Salem, North Carolina and Institute of Aerobics \\ Research, Dallas, Texas, USA
}

(Received 3 August 1977 - Accepted 28 February 1978)

I. Skinfold thickness, body circumferences and body density were measured in samples of 308 and ninetyfive adult men ranging in age from 18 to 61 years.

2. Using the sample of $308 \mathrm{men}$, multiple regression equations were calculated to estimate body density using either the quadratic or $\log$ form of the sum of skinfolds, in combination with age, waist and forearm circumference.

3. The multiple correlations for the equations exceeded 0.90 with standard errors of approximately $\pm 0.0073 \mathrm{~g} / \mathrm{ml}$.

4. The regression equations were cross validated on the second sample of ninety-five men. The correlations between predicted and laboratory-determined body density exceeded 0.90 with standard errors of approximately $0.0077 \mathrm{~g} / \mathrm{ml}$.

5. The regression equations were shown to be valid for adult men varying in age and fatness.

Anthropometry is a common field method for measuring body density (Behnke \& Wilmore, I974). Brožek \& Keys (195I) were the first to publish regression equations with functions of predicting body density with anthropometric variables. Subsequently, numerous investigators have published equations using various combinations of skinfolds and body circumferences.

The development of generalized equations for predicting body density from anthropometric equations has been found to have certain limitations. First, equations have been shown to be population specific and different equations were needed for samples of men varying in age and body fatness. It was shown that with samples of men differing in age, the slopes of the regression lines were homogeneous, but the intercepts were significantly different (Durnin \& Womersley, 1974; Pollock, Hickman, Kendrick, Jackson, Linnerud \& Dawson, 1976). It was further shown that the slopes of the regression lines of young adult men and extremely lean world class distance runners were not parallel (Pollock, Jackson, Ayres, Ward, Linnerud \& Gettman, 1976). The differences of either slopes or intercepts resulted in bias body density estimates. A related problem has been that linear regression models have been used to derive prediction equations, when research has shown that a curvilinear relationship exists between skinfold fat and body density (Allen, Peng, Chen, Huang, Chang \& Fang, 1956; Chen, Peng, Chen, Huang, Chang \& Fang, 1975; Durnin \& Womersley, 1974). This non-linear relationship may be the reason for the differences in slopes and intercepts.

Durnin \& Womersley (1974) logarithmically transformed the sum of skinfolds to create a linear relationship with body density, but still needed different intercepts to account for age differences. The purpose of this investigation was to derive generalized regression equations that would provide unbiased body density estimates for men varying in age and body composition. Efforts were concentrated on the curvilinearity of the relationship and the function of age on body density.

\footnotetext{
* Present address: Department of Health and Physical Education, University of Houston, Houston, Texas, USA.

$\dagger$ Present address: Cardiovascular Disease Section, Mount Sinai Medical Center, University of Wisconsin, School of Medicine, Milwaukee, Wisconsin, USA.
} 
Table I. Physical characteristics of the validations and cross-validation samples*

\begin{tabular}{|c|c|c|c|c|c|c|}
\hline \multirow[b]{2}{*}{ Variable } & \multicolumn{3}{|c|}{$\begin{array}{l}\text { Validation sample } \\
\qquad(n \text { 308) }\end{array}$} & \multicolumn{3}{|c|}{$\begin{array}{l}\text { Cross-validation sample } \\
\text { ( } n \text { 95) }\end{array}$} \\
\hline & Mean & SD & Range & Mean & SD & Range \\
\hline Age (year) & $32 \cdot 6$ & $10 \cdot 8$ & I 8-6I & $33 \cdot 3$ & II 5 & I 8-59 \\
\hline Height (m) & $1 \cdot 792$ & 0.065 & $1 \cdot 63-2 \cdot 01$ & $1 \cdot 784$ & 0.059 & $I \cdot 66-I \cdot 91$ \\
\hline Weight $(\mathrm{kg})$ & $74 \cdot 8$ & $11 \cdot 8$ & $54-123$ & $77 \cdot 6$ & II 7 & $53-102$ \\
\hline Body density $(\mathrm{g} / \mathrm{ml})$ & I. 0586 & 0.0181 & I.0I6I-I'0996 & $\mathrm{I} \cdot 0564$ & 0.0188 & I.0259-I.0998 \\
\hline Fat $(\%) \dagger$ & $17 \cdot 7$ & $8 \cdot 0$ & $1-33$ & I $8 \cdot 7$ & $8 \cdot 3$ & $1-33$ \\
\hline Lean weight (kg) & 63.9 & $7 \cdot 4$ & $48-100$ & $62 \cdot 4$ & $6 \cdot 7$ & $47-81$ \\
\hline Fat weight $(\mathrm{kg})$ & 14.5 & $7 \cdot 9$ & $I-42$ & $15 \cdot 2$ & $7 \cdot 9$ & I-3I \\
\hline Sum 7 skinfolds $(\mathrm{mm})$ & $122 \cdot 6$ & $52 \cdot 0$ & $32-272$ & $124 \cdot 7$ & $53 \cdot I$ & $31-222$ \\
\hline Log 7 skinfolds $(\mathrm{mm})$ & $4 \cdot 70$ & 0.49 & $3 \cdot 47-5 \cdot 61$ & 471 & 0.53 & $3.43-5.40$ \\
\hline Sum 3 skinfolds $(\mathrm{mm}) \ddagger$ & $59 \cdot 4$ & $24 \cdot 3$ & $14-118$ & $59 \cdot 2$ & $25 \cdot 4$ & IO-III \\
\hline Log 3 skinfolds (mm) & 3.98 & 0.49 & $2 \cdot 64-4 \cdot 78$ & 3.95 & 0.56 & $2 \cdot 30-4 \cdot 71$ \\
\hline Waist circumference (m) & 0.871 & 0.097 & $0.67-1 \cdot 25$ & 0.874 & 0.1 & $0 \cdot 68-I \cdot 14$ \\
\hline Forearm circumference (m) & 0.288 & 0.019 & $0.22-0.37$ & 0.287 & 0.021 & $0.24-0.39$ \\
\hline
\end{tabular}

\section{METHODS}

A total of 403 adult men between 18 and 6I years of age volunteered as subjects. The sample represented a wide range of men who varied considerably in body structure, body composition, and exercise habits. The subjects were tested in one of two laboratories (Wake Forest University, Winston-Salem, North Carolina and Institute for Aerobics Research, Dallas, Texas) over a period of 4 years. The total sample was randomly divided into a validation sample consisting of 308 men and a cross-validation sample of ninety-five subjects. The validation sample was used to derive generalized regression equations and were cross-validated with the second sample. This procedure has been recommended by Lord \& Novick (1968). The physical characteristics of the two samples are presented in Table I.

Upon arrival at the laboratory, the subjects were measured for standing height to the nearest $0.01 \mathrm{~m}(0.25 \mathrm{in})$ and for body-weight to the nearest $\mathrm{I} 0 \mathrm{~g}$. Skinfold fat was measured at the chest, axilla, triceps, subscapula, abdomen, supra-iliac, and thigh with a Lange skinfold fat caliper, manufactured by Cambridge Scientific Industries, Cambridge, Maryland, USA.

Recommendations published by the Committee on Nutritional Anthropometry of the Food and Nutrition Board of the National Research Council were followed in obtaining values for skinfold fat (Keys, I956). A previous study (Pollock, Hickman et al. 1976) showed that waist and forearm circumference accounted for body density variance beyond skinfold fat, and for this reason, were included in this study. Waist and forearm circumferences were measured to the nearest $1 \mathrm{~mm}$ with a Lufkin steel tape, manufactured by the Lufkin Rule Company, Apex, North Carolina, USA. The procedures and location of the anthropometric sites measured were shown and described by Behnke \& Wilmore (1974).

The hydrostatic method was used to determine body density. Underwater weighing was conducted in a fibreglass tank in which a chair was suspended from a Chatillon $15 \mathrm{~kg}$ scale. The hydrostatic weighing procedure was repeated six to ten times until three similar readings to the nearest $20 \mathrm{~g}$ were obtained (Katch, 1968). Water temperature was recorded after each trial. Residual volume was determined by either the nitrogen washout or helium dilution technique. The procedure for determining body density followed the method out- 
Table 2. Regression analysis for predicting body density using the sum of seven skinfolds in adult men aged $\mathrm{I} 8-6 \mathrm{I}$ years $\dagger$

\begin{tabular}{|c|c|c|c|c|c|}
\hline Source of variance & $\begin{array}{l}\text { Degrees of } \\
\text { freedom }\end{array}$ & $\begin{array}{l}\text { Sum of } \\
\text { squares }\end{array}$ & $\begin{array}{l}\text { Mean } \\
\text { square }\end{array}$ & $\begin{array}{c}\text { F, ratio } \\
\text { for statistical } \\
\text { significance }\end{array}$ & $\begin{array}{l}\text { Standard regression } \\
\text { certificate for } \\
\text { full model }\end{array}$ \\
\hline & & \multicolumn{4}{|c|}{ Sum of seven skinfolds } \\
\hline Full model & 5 & 0.08418 & 0.01684 & $336 \cdot 80^{*}$ & - \\
\hline Skinfold fat & (2) & 0.07878 & 0.03939 & $787 \cdot 20^{*}$ & - \\
\hline Linear & I & $(0.07757)$ & 0.07757 & $1551 \cdot 40^{*}$ & $-I \cdot 18$ \\
\hline Quadratic & I & $(0.00121)$ & 0.00121 & $24 \cdot 20^{*}$ & 0.53 \\
\hline Age & (1) & 0.00279 & 0.00279 & $55 \cdot 80^{*}$ & -0.14 \\
\hline Circumferences & (2) & 0.00261 & 0.00261 & $52 \cdot 20^{*}$ & - \\
\hline Waist & 一 & - & $\rightarrow$ & - & -0.32 \\
\hline Forearm & - & - & - & - & 0.20 \\
\hline \multirow[t]{2}{*}{ Residual } & 302 & 0.01612 & 0.00005 & - & - \\
\hline & & \multicolumn{4}{|c|}{ Log transformation of seven skinfolds } \\
\hline Full model & 4 & 0.08425 & 0.02106 & $421 \cdot 20^{*}$ & - \\
\hline Log skinfold fat & (I) & 0.07706 & 0.07706 & $1541 \cdot 20^{*}$ & -0.64 \\
\hline Age & (I) & 0.00284 & 0.00284 & $56 \cdot 80^{*}$ & -0.13 \\
\hline Circumferences & (2) & 0.00435 & 0.00435 & $87^{\circ} 00^{*}$ & - \\
\hline Waist & 一 & 一 & - & - & -0.38 \\
\hline Forearm & 一 & 一 & - & - & $0 \cdot 23$ \\
\hline Residual & 303 & 0.01605 & 0.00005 & - & - \\
\hline
\end{tabular}

lined by Goldman \& Buskirk (I96I). Body density was calculated from the formula of Brožek, Grande, Anderson \& Keys (1963) and fat percentage according to Siri (1961) (see Table I).

In a factor analysis study, it was shown (Jackson \& Pollock, 1976) that skinfolds measured the same factor; therefore, the skinfolds were summed. The sum of several measurements provides a more stable estimate of subcutaneous fat. A second sum consisting of chest, abdomen and thigh skinfolds was also derived. These three skinfolds were selected because of their high intercorrelation with the sum of seven and it was thought that they would provide a more feasible field test. The sum of skinfolds were also logarithmically transformed so that they could be compared with the work of Durnin \& Womersley (I974).

Regression analysis (Kerlinger \& Pedhazur, 1973) was used to derive the generalized equations. Polynomial models were used to test if the relationship between body-density and the sum of skinfolds was curvilinear. 'Step-down' analysis was used to determine if age, and then age in combination with the circumference measurements, accounted for additional body-density variance beyond that attributed to the sum of skinfolds. The crossvalidation procedures recommended by Lord \& Novick (1968) were followed to determine if the equations derived on the validation sample accurately predicted the body density of the cross-validation sample.

\section{RESULTS}

Table I shows that basic results derived from the validation and cross-validation samples including natural $\log$ transformations of the sum of skinfolds. The standard deviations and ranges showed that the men differed considerably in both age and body composition. Tables 2 and 3 show the regression analysis using the sum of seven and sum of three skin- 
Table 3. Regression analysis for predicting body density using the sum of three skinfolds $\dagger$

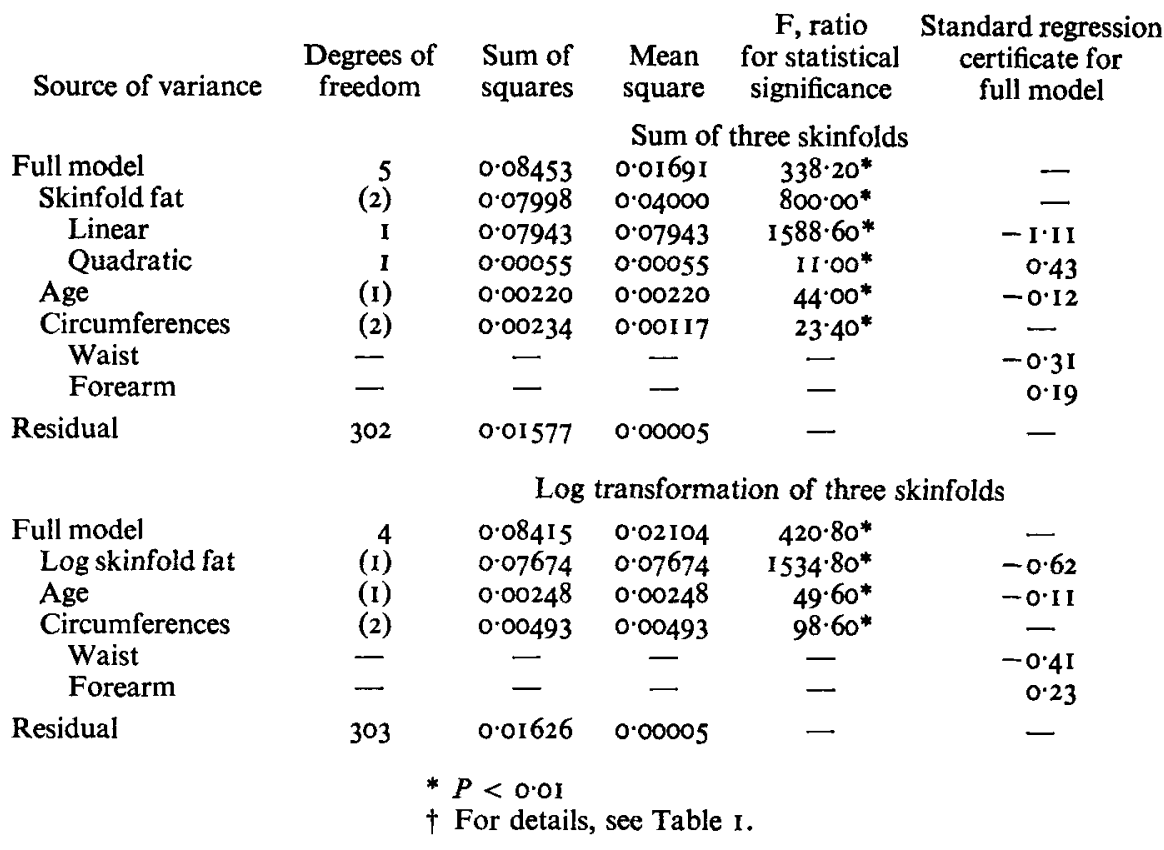

folds respectively. The correlation between the sum of three and seven skinfolds was 0.98 ; thus, the regression analyses for these variables were nearly identical. The full model consisted of either the linear and quadratic or the $\log$ transformed sum of skinfolds in combination with age, and body circumferences. The multiple correlations for these full models were nearly identical, ranging from 0.915 to 0.918 . Regression equations for the full models may be found in Table 4 .

Since the full models were significant, the step-down analysis was conducted to determine if each variable accounted for a significant proportion of body-density variance. The first analysis within the full model was to determine if the relationship between skinfold fat and body density was linear or quadratic. This was found to be quadratic which supported the findings of other investigators (Allen et al. 1956; Chen et al. 1975; Durnin \& Womersley, I974). Durnin \& Womersley (I974) used a log transformation to form a linear relationship between skinfold fat and body density. For this reason, only the linear relationship with log transformed skinfolds was used.

Age was the next variable entered into the regression model and it accounted for a signifcant proportion of body-density variance beyond the log-transformed or quadratic form of skinfolds. Waist and forearm circumference were the last two variables entered into the full model and these measures accounted for a significant proportion of body-density variance beyond age and skinfold fat.

The standardized regression coefficients for the full model are presented in Tables 2 and 3. The magnitude of these weights represented the relative importance of each variable with the effects of the other variables held constant. These statistics showed that the linear and quadratic components accounted for most of the body density variance. The negative weighting of the sum of skinfolds and positive weighting of the squared sum of skinfolds represent the quadratic relationship between body density and the sum of skinfolds. The 
Table 4. Generalized regression equations for predicting body density $(B D)$ of adult men ages I 8-61 years*

Anthropometric variables

Regression equation

Sum of seven skinfolds

\begin{tabular}{|c|c|c|c|c|}
\hline$S, S^{2}$, age & $\begin{aligned} \mathrm{BD}= & \mathrm{I} \cdot \mathrm{I} \mathrm{I} 200000-0.00043499\left(X_{1}\right)+0.00000055\left(X_{1}\right)^{2} \\
& -0.00028826\left(X_{3}\right)\end{aligned}$ & I & 0.902 & 0.0078 \\
\hline$S, S^{2}$, age, $C$ & $\begin{aligned} \mathrm{BD}= & \mathrm{I} \cdot 10100000-0.00041150\left(X_{1}\right)+0.00000069\left(X_{1}\right)^{2} \\
& -0.00022631\left(X_{3}\right)-0.0059239\left(X_{4}\right)+0.0190632\left(X_{5}\right)\end{aligned}$ & 2 & 0.916 & 0.0073 \\
\hline $\log S$, age & $\mathrm{BD}=1.21394-0.03101\left(\log X_{1}\right)-0.00029\left(X_{3}\right)$ & 3 & 0.893 & 0.0082 \\
\hline $\log S$, age, $C$ & $\begin{aligned} \mathrm{BD}= & 1.17615-0.02394\left(\log X_{1}\right)-0.00022\left(X_{\mathrm{a}}\right) \\
& -0.0070\left(X_{4}\right)+0.02120\left(X_{5}\right)\end{aligned}$ & 4 & 0.917 & 0.0073 \\
\hline \multicolumn{5}{|c|}{ Sum of three skinfolds } \\
\hline$S, S^{2}$, age $\quad(5)$ & $\begin{aligned} \mathrm{BD}= & \mathrm{I} \cdot 1093800-0.0008267\left(X_{2}\right)+0.0000016\left(X_{2}\right)^{2} \\
& -0.0002574\left(X_{3}\right)\end{aligned}$ & 5 & 0.905 & 0.0077 \\
\hline$S, S^{2}$, age, $C(6)$ & $\begin{aligned} \mathrm{BD}= & 1.0990750-0.0008209\left(X_{2}\right)+0.0000026\left(X_{2}\right)^{2} \\
& -0.0002017\left(X_{3}\right)-0.005675\left(X_{4}\right)+0.018586\left(X_{5}\right)\end{aligned}$ & 6 & 0.918 & 0.0072 \\
\hline $\log S$, age $\quad(7)$ & $\mathrm{BD}=\mathrm{I} \cdot 18860-0.03049\left(\log X_{2}\right)-0.00027\left(X_{3}\right)$ & 7 & 0.888 & 0.0083 \\
\hline $\log S$, age, $C(8)$ & $\begin{aligned} \mathrm{BD}= & \mathrm{I} \cdot 15737-0.02288\left(\log X_{2}\right)-0.00019\left(X_{3}\right) \\
& -0.0075\left(X_{4}\right)+0.0223\left(X_{5}\right)\end{aligned}$ & 8 & 0.915 & 0.0073 \\
\hline
\end{tabular}

$S$, Sum of skinfolds; $C$, circumference; $X_{1}$, sum of chest, axilla, triceps, subscapula, abdomen, suprailium and front thigh skinfolds; $X_{2}$, sum of chest, abdomen and thigh skinfolds; $X_{3}$, age; $X_{4}$, waist circumference; $X_{5}$, forearm circumference.

* For details, see Table I.

Table 5. Cross-validation of generalized equations on the calibration sample ( $n$ 95)

\begin{tabular}{|c|c|c|c|c|c|}
\hline \multirow[b]{2}{*}{ Variables } & \multirow[b]{2}{*}{ Equation no.* } & \multirow[b]{2}{*}{$r_{y w^{\prime}}$} & \multirow[b]{2}{*}{ SE† } & \multicolumn{2}{|c|}{ Range of SE } \\
\hline & & & & Agef & Fat\$ \\
\hline & & \multicolumn{4}{|c|}{ Sum of seven skinfolds } \\
\hline$S, S^{2}$, age & $\mathbf{I}$ & 0.915 & 0.0078 & $0.0064-0.0085$ & $0.0066-0.0092$ \\
\hline$S, S^{2}$, age, $C$ & 2 & 0.915 & 0.0077 & $0.0057-0.0094$ & $0.0067-0.0084$ \\
\hline $\log \mathrm{S}$, age & 3 & 0.914 & 0.0078 & $0.0055-0.0085$ & $0.0054-0.009 \mathrm{I}$ \\
\hline $\log S$, age, $C$ & 4 & 0.913 & 0.0078 & $0.006 \mathrm{r}-0.0098$ & $0.0064-0.0091$ \\
\hline & & \multicolumn{4}{|c|}{ Sum of three skinfolds } \\
\hline $\begin{array}{l}S, S^{2}, \text { age } \\
S, S^{2} \text { age, } C\end{array}$ & $\begin{array}{l}5 \\
6\end{array}$ & $\begin{array}{l}0.917 \\
0.920\end{array}$ & $\begin{array}{l}0.0077 \\
0.0076\end{array}$ & $\begin{array}{l}0.0066-0.0083 \\
0.0066-0.0092\end{array}$ & $\begin{array}{l}0.0057-0.0087 \\
0.0058-0.0087\end{array}$ \\
\hline $\log S$, age & 7 & 0.904 & 0.0085 & $0.0064-0.0112$ & $0.0047-0.0102$ \\
\hline $\log S$, age, $C$ & 8 & 0.910 & 0.0082 & $0.0057-0.0100$ & $0.0060-0.0097$ \\
\hline
\end{tabular}

$S$, sum of skinfolds; $C$, circumference; $r_{y y^{\prime}}$, correlation between predicted $\left(y^{\prime}\right)$ and laboratory determined (y) body density.

* For details, see Table 4 .

$\dagger \mathrm{SE}=\sqrt{ }\left[\Sigma\left(y^{\prime}-y\right)^{2} / n\right]$.

\$ Age (years) categories; $\left\langle 19^{\circ} 9,20 \cdot 0-29 \cdot 9,39^{\circ} 0-39 \cdot 9,40 \cdot 0-49 \cdot 9,\right\rangle 50 \cdot 0$.

$\S$ Fat $(\%)$ categories: $\left\langle 9.9,10 \cdot 0-14^{\circ} 9,15^{\circ} 0-19.9,20^{\circ} 0-24^{\circ} 9\right\rangle\left\langle 25^{\circ} 0\right.$.

positive weighting for waist and negative weighting for forearm is consistent with the results reported by Katch \& McArdle (1973).

Table 4 lists selected raw score equations and the equation's multiple correlation and standard error. The high multiple correlations are due partially to the heterogeneous sample studied. However, the standard errors are low and well within the values reported by other 


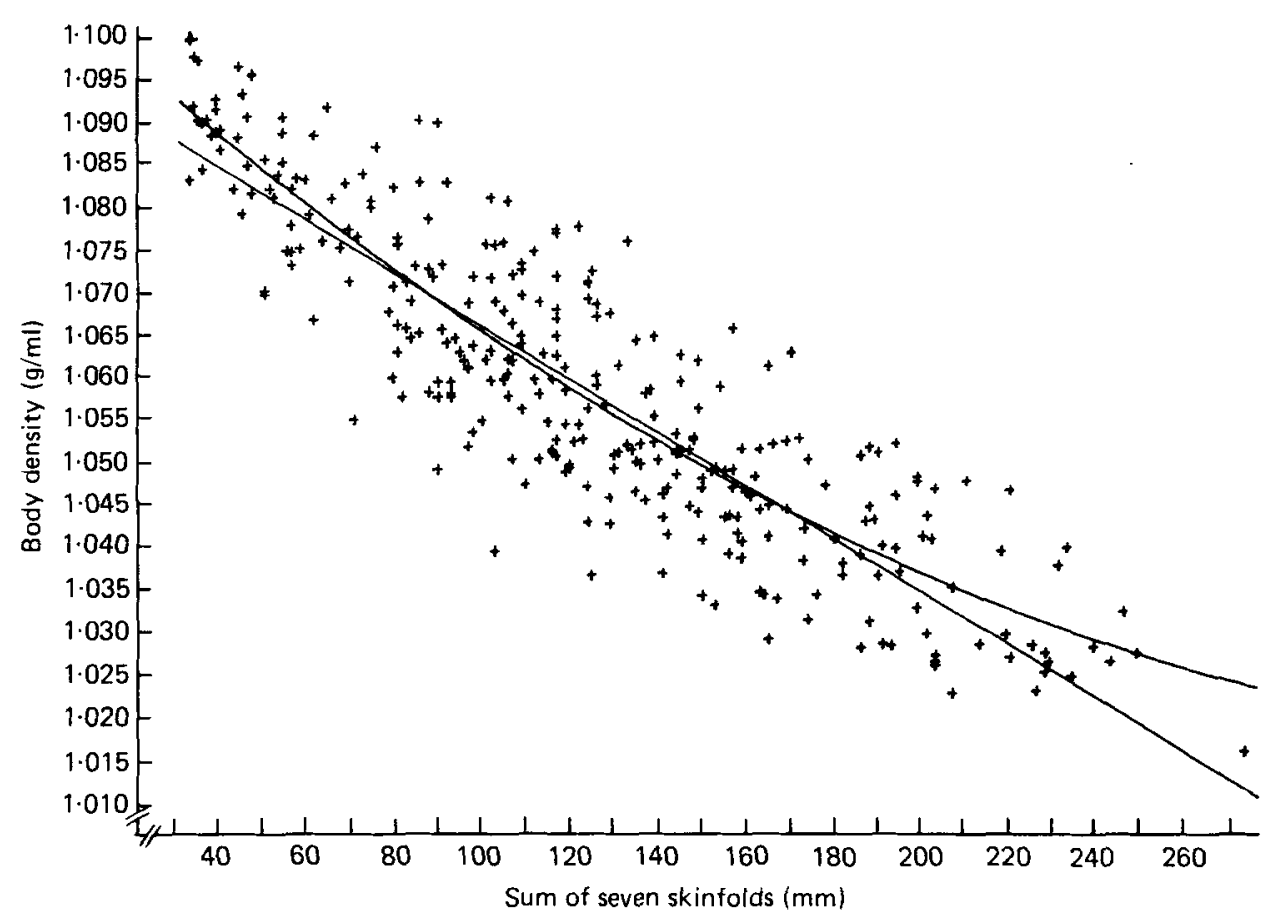

Fig. I. Scattergram of body density and sum of seven skinfolds, with the linear quadratic regression lines, for adult men aged $18-61$ years (for details, see Table 1 ). Details of generalized regression equations are given in Table 4.

investigators (Katch \& McArdle, 1973; Pascale, Grossman, Sloane \& Frankel, 1956; Pollock, Hickman et al. 1976; Sloan, 1967; Wilmore \& Behnke, 1969; Wright \& Wilmore, 1974) who used more homogeneous samples.

The 'raw score' equations were applied to the anthropometric results of the crossvalidation sample. The cross-validation analysis is presented in Table 5. The product moment correlation between laboratory determined and estimated body density were all higher than 0.90 , and the standard errors were within the range found with the validation sample results.

The cross-validation sample was then reduced first, to five age categories, and next, to levels of body fat content by five fat $(\%)$ categories. The ranges of standard errors for these different categories are also presented in Table 5. With the exception of the log equations, none of the standard errors exceeded $0.0100 \mathrm{~g} / \mathrm{ml}$. Since these standard error estimates were based on sample sizes that varied from ten to thirty-three cases, more variability was expected. These analyses showed that the regression equations accurately predicted body density for samples differing in age and fatness.

\section{DISCUSSION}

The findings of several studies (Durnin \& Womersley, 1974; Pollock, Hickman et al. 1976) showed that regression equations were population specific. The application of regression equations derived on one sample, but applied to other samples that differed in age and fatness, produced biassed body density estimates. The findings of this study showed that some of this bias may be attributed to the use of linear regression models because the 
relationship between skinfold fat and body density was quadratic. This is shown by the 'scattergram' between the sum of seven skinfolds and body density which is presented as Fig. I. Both linear and quadratic regression lines are provided. The differences between the two regression lines showed where the largest bias prediction errors would occur. This was at the ends of the bivariate distribution. For example, the fat $(\%)$ differences between the linear and quadratic sum of seven skinfold equations for 250 and $40 \mathrm{~mm}$ of skinfold fat were 2.9 and $\mathrm{x} \cdot 3$ fat $(\%)$ respectively, while the difference was only 0.5 fat $(\%)$ for $150 \mathrm{~mm}$.

In a previous study (Pollock, Jackson et al. 1976), it was found that the slopes of the regression lines of lean world-class distance runners and young adult men were not parallel. The prediction of the body-density of the lean runner with linear equations derived on a sample of young adult men systematically underestimated the body density of these lean subjects. This source of systematic error is documented by the differences between the linear and quadratic regression lines shown in Fig. I and confirms the need for quadratic equations.

It has been shown that the intercepts of the regression lines of young adult men and older (+35 years) and fatter men were different (Pollock, Hickman et al. 1976). Since the relationship between body-density and skinfold fat was quadratic, the differences in intercepts could be partly due to the use of linear regression equations. The results reported by Durnin \& Womersley (1974) showed, however, that age was also responsible for the intercept differences. Durnin \& Womersley (1974) used a logarithmic transformation of the sum of four skinfolds. This transformation changed the quadratic relationship between body density and the sum of skinfolds, in the 'raw score' form, into a linear relationship. With male subjects who ranged from I 6 to 59 years of age, they reported that the slopes for samples divided by to year intervals were parallel, but had different intercepts. This would result in biassed estimates due to age differences, thus Durnin \& Womersley (1974) provided five different equations which had the same slope, but different intercepts.

The finding of this study, that age accounted for a significant proportion of body-density variation beyond that attributed to quadratic or logarithmic sum of skinfolds agreed with the findings reported by Durnin \& Womersley (1974). They suggested that this agerelationship may be due to a higher proportion of total body fat being situated internally and a decrease in the density of fat-free mass. The decrease in fat-free mass was primarily attributed to skeletal changes (Durnin \& Womersley, 1974). In the present study, the use of age as an independent variable accounted for intercept difference, and eliminated the need for several different age-adjusted equations. The cross-validation results documented the accuracy of a generalized equation for samples differing in age and fatness. The standard errors found in these analyses are within the range reported by Durnin \& Womersley (1974). Using 209 men who varied in age from 16 to 72, Durnin \& Womersley (1974) reported standard errors that ranged from 0.0059 to $0.0117 \mathrm{~g} / \mathrm{ml}$ for prediction equations derived for similar age groups.

The multiple correlations for the generalized equations derived with the logarithmic or quadratic sum of skinfolds were nearly identical. The results of the cross-validation analysis suggested that the quadratic equations were more accurate. The standard errors tended to be lower for the total sample and less variable for the total sample and for the different age and fat $(\%)$ categories. This was expecially true for the sum of three skinfolds.

The generalized equations provided valid and accurate body-density estimates with adult men varying in age and fatness. The cross-validation of equations is important because one is not certain that equations developed with one sample will predict body density with the same accuracy when applied to the data of a different sample. The best evidence is provided by the standard error when the equation is cross-validated on the second sample. The standard errors for the cross-validation analysis were low and nearly identical to the standard errors found with the validation sample. This provided the strongest evidence 
that the generalized equations were accurate and valid for use with adult men varying in age and body density.

\section{REFERENCES}

Allen, T. H., Peng, M. T., Chen, K. P., Huang, T. F., Chang, C. \& Fang, H. S. (1956). Metabolism 5, 346. Behnke, A. R. \& Wilmore, J. H. (1974). Evaluation and Regulation of Body Build and Composition. Englewood Cliffs: Prentice-Hall.

Brožek, J., Grande, F., Anderson, J. T. \& Keys, A. (1963). Ann. N.Y. Acad. Sci. ı1o, I 3.

Brožek, J. \& Keys, A. (195I). Br. J. Nutr. 5 , I94.

Chen, S., Peng, M. T., Chen, K. P., Huang, T. F., Chang, C. \& Fang, H. S. (1975). J. appl. Physiol. 39, 825.

Durnin, J. V. G. A. \& Rahaman, M. M. (1967). Br. J. Nutr. 21, 68I.

Goldman, R. F. \& Buskirk, E. R. (196I). In Techniques for Measuring Body Composition, p. 78 [J. Brožek and A. Henschels, editors]. Washington, DC: National Academy of Science.

Jackson, A. S. \& Pollock, M. L. (1976). Med. Sci. Sports 8, 196.

Katch, F. I. (1968). Research Quarterly 39, 993.

Katch, F. I. \& McArdle, W. D. (I973). Human Biol. 45, 445.

Kerlinger, F. N. \& Pedhazur, E. S. (1973). Multiple Regression in Behavioral Research. New York: Holt, Rinehart and Winston.

Keys, A. (1956) Human Biol. 28, 111 .

Lord, F. M. \& Novick, M. R. (1968). Statistical Theories of Mental Test Scores, pp. 285-288. Reading, Mass.: Addison-Wesley.

Pascale, L. R., Grossman, M. I., Sloane, H. S. \& Frankel, T. (1956). Human Biol. 28, 165.

Pollock, M. L., Hickman, T., Kendrick, Z., Jackson, A. S., Linnerud, A. C. \& Dawson, G. (1976). J. appl. Physiol. 40, 300.

Pollock, M. L., Jackson, A. S., Ayres, J., Ward, A., Linnerud, A. \& Gettman, L. (1976). Ann. N.Y. Acad. Sci, 301, 361.

Siri, W. E. (I96I). In Techniques for Measuring Body Composition, p. 223 [J. Brožek and A. Hanschels, editors]. Washington DC: National Academy of Science.

Sloan, A. W. (1967). J. appl. Physiol. 23, 31 I.

Wilmore, J. H. \& Behnke, A. R. (1969). J. appl. Physiol. 27, 25.

Wright, H. F. \& Wilmore, J. H. (1974). Aerospace Med. 45, 30 I. 